\title{
Contabilidade Rural e de Custos aplicada à atividade leiteira: um estudo de caso em uma propriedade rural do Oeste de Santa Catarina
}

Cristian Bau Dal Magro
Doutorado em andamento em Ciências Contábeis pela Universidade Regional de

Blumenau - FURB

Professor da Fundação Universidade Regional de Blumenau - FURB Rua Antônio da Veiga, 140. Itoupava Seca. Blumenau/SC. CEP: 89012-900

E-mail: crisbau@uceff.edu.br

Mara Vogt

Doutorado em andamento em Ciências Contábeis pela Universidade Regional de

Blumenau - FURB

Professora das Faculdades de Itapiranga - FAI

Rua Carlos Kummer, 100. Bairro Universitário/SC. CEP: 89896-000

E-mail: maravogtcco@gmail.com

Larissa Degenhart

Doutorado em andamento em Ciências Contábeis pela Universidade Regional de

Blumenau - FURB

Rua Antônio da Veiga, 140. Itoupava Seca. Blumenau/SC. CEP: 89012-900

E-mail: lari_ipo@hotmail.com

Leila Chaves Cunha

Doutorado em andamento em Ciências Contábeis pela Universidade Regional de

Blumenau - FURB

Coordenadora de Curso da Universidade para o Desenvolvimento do Alto Vale do Itajaí

- UNIDAVI

Rua Guilherme Gemballa, 13. Jardim América, Rio do Sul/SC. CEP: 89160-000

E-mail: leila@unidavi.edu.br

Fabricia Silva da Rosa

Doutorado em Engenharia de Produção pela Universidade Federal de Santa Catarina -

UFSC

Professora da Universidade Federal de Santa Catarina - UFSC Campus Reitor João David Ferreira Lima, s/n. Trindade. Florianópolis/SC. CEP: 88040-

900

E-mail: fabriciasrosa@hotmail.com

\section{RESUMO}

A atividade agropecuária contribui significativamente para 0 desenvolvimento econômico e social do mundo, pois gera emprego e renda para um grande número de 
Contabilidade Rural e de Custos aplicada à atividade leiteira: um estudo de caso em uma propriedade rural do Oeste de Santa Catarina Cristian Bau Dal Magro, Mara Vogt, Larissa Degenhart, Leila Chaves Cunha, Fabricia Silva da Rosa

pessoas. Dessa forma, para otimizar os resultados das atividades, é preciso planejar e controlar sua produtividade e lucratividade. Para tanto, este estudo objetivou identificar a contribuição da contabilidade rural e de custos para a melhoria na gestão da atividade leiteira em uma propriedade rural localizada no Oeste de Santa Catarina. Realizou-se uma pesquisa exploratória, documental e quantitativa, por meio de um estudo de caso, em uma propriedade rural, com acompanhamento no período de doze meses, durante o ano de 2013. Os resultados indicam que o mês de julho apresenta maior margem bruta, produtividade e lucratividade na atividade leiteira. A lucratividade média mensal por vaca na propriedade em estudo é de $R \$ 73,60$, podendo variar em outras propriedades e/ou na propriedade em estudo, de acordo com a raça de animais que produzem leite. Por fim, conclui-se que a contabilidade rural e a de custos são técnicas conjuntas que, se utilizadas de maneira correta, possibilitam resultados importantes para a melhoria na gestão, visando à eficiência e competitividade da atividade leiteira em pequenas propriedades rurais.

Palavras-chave: Contabilidade Rural. Custos. Atividade Leiteira.

\section{Rural Accounting and costs applied to dairy farming: a case study in a rural property of the West of Santa Catarina}

\section{ABSTRACT}

The agricultural activity contributes significantly to the economic and social development of the world, because it generates jobs and income for a large number of people. Thus, to optimize the results of the activities you need to plan and control their productivity and profitability. Therefore, this study aimed to identify the contribution of rural and cost accounting for the improvement in the management of dairy farming in a rural property located in the West of Santa Catarina. We conducted an exploratory, documental and quantitative research through a case study in a rural property, since it was carried out a case study on a farm, and was accompanied data during the twelve months in the year 2013. The results indicate that the month of July has a higher gross margin, productivity and profitability in the dairy business. The average monthly profitability per cow on the property under consideration is $\mathrm{R} \$ 73.60$, but may differ in other properties and/or property under study according to breed animals that produce milk. Finally, it is concluded that rural and cost accounting are joint techniques that, if they are used properly, enable significant results to improve management to the efficiency and competiveness of dairy farming on small farms.

Keywords: Rural accounting. Costs. Dairy activity. 
Contabilidade Rural e de Custos aplicada à atividade leiteira: um estudo de caso em uma propriedade rural do Oeste de Santa Catarina Cristian Bau Dal Magro, Mara Vogt, Larissa Degenhart, Leila Chaves Cunha, Fabricia Silva da Rosa

\section{INTRODUÇÃO}

Atualmente, a agricultura familiar é um assunto relevante para o desenvolvimento sustentável das propriedades rurais, com vistas a promover uma vida saudável a toda a sociedade. Também é considerada predominante na produção de alimento tanto nos países desenvolvidos quanto nos países em desenvolvimento (TOADER e ROMAN, 2015).

Desse modo, a atividade agropecuária contribui significativamente para 0 desenvolvimento econômico e social do mundo, pois gera emprego e renda para um grande número de pessoas. Além disso, na grande maioria, é desenvolvida em regime familiar. O Brasil, por ser um país com grande extensão territorial e condições climáticas favoráveis, faz com que o agronegócio encontre um vasto campo para desenvolver suas culturas com êxito (HOFER et al., 2011).

No contexto agropecuário brasileiro, o Instituto Brasileiro de Geografia e Estatística (IBGE) adotou os conceitos de "agricultura familiar", conforme os critérios estabelecidos pela Lei no 11.326/2006, e, para os estabelecimentos que não se enquadram nesta modalidade, designou-os de "não familiares". No censo realizado no ano de 2006, foram identificados 4.367.902 estabelecimentos da agricultura familiar, 0 que representa $84,4 \%$ dos estabelecimentos brasileiros; ocupavam $24,3 \%$ da área total dos estabelecimentos agropecuários. Os estabelecimentos não familiares ocupavam $75,7 \%$ da área, apesar de representarem 15,6\% do total dos estabelecimentos; a área média dos estabelecimentos familiares era de 18,37 hectares, e a dos não familiares, de 309,18 hectares (IBGE, 2009).

De acordo com Costa, Libonati e Rodrigues (2004), o setor agrícola possui algumas particularidades que o diferenciam dos demais setores da economia, pois é o clima que determina quais serão as épocas certas do plantio de determinadas culturas, colheitas, escolha das espécies, vegetais e animais a serem cultivados nas propriedades rurais.

Nesse contexto, os sistemas de informação são considerados imprescindíveis para empreendimentos agropecuários, pois, para que se desenvolvam, precisam de um 
Contabilidade Rural e de Custos aplicada à atividade leiteira: um estudo de caso em uma propriedade rural do Oeste de Santa Catarina Cristian Bau Dal Magro, Mara Vogt, Larissa Degenhart, Leila Chaves Cunha, Fabricia Silva da Rosa

sistema integrado que seja capaz de orientar os mais diversos tipos de atividades, nas diferentes etapas do processo produtivo e nos mais variados níveis institucionais (MARQUES, 2002).

O desenvolvimento de novas tecnologias de informação, a biotecnologia, as mudanças no perfil do consumidor e a concorrência, ligados à complexidade e ao dinamismo do mercado atual, afetam a gestão rural de forma significativa e, consequentemente, as decisões estratégicas, precisando alterar as rotinas para resolver os problemas até então tidos como insolúveis, principalmente pelo produtor de leite (MARION e SEGATTI, 2006).

Um sistema de gestão adequado à pecuária de leite necessita compreender as características do sistema produtivo e, além disso, dos medidores de eficiência dessa atividade. Integrando esses elementos, será possível compreender o complexo da pecuária leiteira, que serve de referência para implementar um sistema de gestão (CORREA, 2003).

Vale ressaltar que o sistema de gestão pode contemplar tanto a contabilidade rural quanto o sistema de custos. De acordo com Crepaldi (2004), a função da contabilidade rural é controlar o patrimônio das entidades, apurar o resultado e prestar informações sobre o patrimônio e sobre o resultado das entidades aos diversos usuários das informações contábeis.

Por outro lado, a contabilização de custos é uma necessidade imperiosa para todas as empresas que almejam monitorar escalas de competitividade dentro dos ramos empresariais nos quais atuem. No entanto, as empresas que atuam no agronegócio se deparam com particularidades operacionais específicas em função do grau de diversificação. Esta dificuldade reside tanto no controle dos seus elementos, de forma a obter uma correta apropriação dos custos de cada produto ou atividade econômica existente, bem como sobre os procedimentos de rateio (CALLADO e CALLADO, 2006).

Diante desse contexto, identificaram-se na literatura diversos estudos desenvolvidos com o intuito de analisar a contabilidade rural como os de Costa et al. (2013), Nascimento et al. (2013), Kruger et al. (2013), Ruberto et al. (2013) e Novo et al. 
Contabilidade Rural e de Custos aplicada à atividade leiteira: um estudo de caso em uma propriedade rural do Oeste de Santa Catarina Cristian Bau Dal Magro, Mara Vogt, Larissa Degenhart, Leila Chaves Cunha, Fabricia Silva da Rosa

(2013). Porém, nenhum destes buscou verificar o proposto neste trabalho, identificando-se assim a lacuna da pesquisa.

Frente ao exposto, destaca-se a seguinte questão que norteia o desenvolvimento desta pesquisa: qual a contribuição da contabilidade rural e de custos para a melhoria da gestão da atividade leiteira em uma propriedade rural familiar do Oeste de Santa Catarina? Visando responder a questão apresentada, o objetivo deste estudo é identificar a contribuição da contabilidade rural e de custos para a melhoria na gestão da atividade leiteira em uma propriedade rural familiar do Oeste de Santa Catarina.

A presente pesquisa justifica-se pela importância de se verificar a contribuição da contabilidade rural para a melhoria na gestão das atividades agropecuárias. Contudo, se faz necessário valorizar o planejamento, controle e a gestão empresarial das propriedades rurais, visando ao lucro na atividade. Ainda, justifica-se devido ao fato de - Brasil estar colocado como o $3^{\circ}$ maior produtor de leite do mundo, sendo que a produção nacional cresceu aproximadamente $4,5 \%$ em 2011 , perdendo somente para os Estados Unidos e a Índia (RANKBRASIL, 2014). Além disso, o estudo ainda se justifica devido à complexidade do setor e ao aumento da concorrência. Assim, o processo de gestão necessita ser ágil e apresentar critérios adequados para alcançar o sucesso e cumprir os objetivos, superando restrições do sistema produtivo (CORRÊA, 2003).

Justifica-se também por meio de Medina et al. (2015), pois comentam que há um interesse global envolvendo fatores que contribuam para que a agricultora familiar se torne um setor mais competitivo, o qual proporcionará redução na pobreza e crescimento econômico. Dessa forma, este estudo contribui, oferecendo a visão de que o sistema de contabilidade rural e de custos pode ser um fator adicionado às perspectivas de Medina et al. (2015), o que contribui com a sociedade e com a prática gerencial rural.

A pesquisa foi focada no desenvolvimento de contribuições acerca da importância dos sistemas de contabilidade rural e de custos para o desenvolvimento da agricultura familiar; portanto, foi escolhida uma propriedade rural familiar localizada no Oeste de Santa Catarina. De acordo com Ferrari et al. (2005), a produção de leite tem 
Contabilidade Rural e de Custos aplicada à atividade leiteira: um estudo de caso em uma propriedade rural do Oeste de Santa Catarina Cristian Bau Dal Magro, Mara Vogt, Larissa Degenhart, Leila Chaves Cunha, Fabricia Silva da Rosa

se tornado uma das mais importantes atividades para a inserção econômica da agricultura familiar do Sul do Brasil ao mercado. Além disso, na região Oeste de Santa Catarina, a atividade já era praticada, desde a colonização, pelos agricultores familiares e visava, de maneira geral, ao consumo familiar. Portanto, a expansão do mercado faz com que os agricultores familiares percebam a importância da utilização das informações contábeis padronizadas, visando à competividade da atividade.

\section{REFERENCIAL TEÓRICO}

No referencial teórico, apresenta-se o embasamento necessário ao desenvolvimento do presente estudo. Inicialmente, aborda-se a contabilidade rural e de custos; na sequência, a gestão pecuária leiteira e, por fim, os estudos anteriores para embasar a metodologia proposta neste estudo.

\subsection{Contabilidade Rural e de Custos}

A importância da contabilidade rural em gerar informações para a tomada de decisões deve estar subordinada a uma administração eficiente, que requer conhecimento do negócio, capital, especialização e modernização agropecuária, sendo que, nesses aspectos, a empresa rural apresenta carências, prejudicando o processo de desenvolvimento e a modernização do setor (BORILLI et al., 2005).

De acordo com Matos (2002), conhecer os recursos disponíveis na propriedade rural, por meio da adoção de tecnologias adequadas, que permitem amenizar os custos de produção, possibilita a sustentabilidade para a empresa e a permanência na atividade. A contabilidade rural possui suas normas e princípios baseados na orientação, controle e registro dos atos e fatos que ocorrem e são praticados na empresa rural (CALDERELLI, 2003). Segundo Hofer et al. (2011), a contabilidade rural é aplicada à atividade rural e auxilia na geração de informações para o planejamento e controle das atividades. Para Crepaldi (2012), a contabilidade rural é considerada um dos principais sistemas de controle e informação das empresas rurais, pois fornece informações sobre as condições de expandir o negócio, necessidades da redução de 
Contabilidade Rural e de Custos aplicada à atividade leiteira: um estudo de caso em uma propriedade rural do Oeste de Santa Catarina Cristian Bau Dal Magro, Mara Vogt, Larissa Degenhart, Leila Chaves Cunha, Fabricia Silva da Rosa

custos ou despesas e, de que forma, buscar recursos, tendo por finalidade o planejamento.

Contudo, o sucesso da empresa rural não consiste apenas em apresentar uma elevada produtividade, em função da tecnologia utilizada, mas, sim, em controlar os custos de produção. Desse modo, se faz necessário entender como gerenciar a produtividade, para assim alcançar resultados desejados e auferir bons lucros (MARION, 2012).

Vilckas (2004) destaca que o empreendimento rural caracteriza-se por diversas variáveis que dificultam o processo de planejamento da produção, como é o caso da dependência de recursos naturais, sazonalidade de mercado, perecibilidade do produto, ciclo biológico dos vegetais e animais, tempo de maturação dos produtos e retorno do investimento. Costa, Libonati e Rodrigues (2004) e Crepaldi (2012) salientam que, na atividade agrícola, o exercício social termina a partir do momento em que se finda o ano agrícola, ou seja, período de 12 meses, que engloba o início do cultivo até o momento da colheita.

Assim, empresas rurais serão competitivas se, em níveis de gerência, adotarem técnicas administrativas, possibilitando o suporte informacional adequado para a contabilidade. Para tanto, a contabilidade rural e de custos é uma área do conhecimento que a cada dia mais vem absorvendo os avanços científicos e tecnológicos, para que os gestores possam desfrutar de informações seguras que os auxiliem na tomada de decisões (MARQUES, 2002).

Nesse contexto, Borilli et al. (2005) ressaltam que a contabilidade desempenha importante papel como ferramenta gerencial, por meio de informações que possibilitam o planejamento, controle e tomada de decisão, fazendo com que as propriedades rurais se transformem em empresas capazes de acompanhar a evolução do setor, principalmente no que diz respeito aos objetivos e atribuições voltados à administração financeira, controle dos custos, comparação dos resultados e diversificação de culturas.

Argilés e Slof (2001) comentam que o setor agrícola, por muito tempo, ganhou pouca atenção de pesquisadores, profissionais e organismos de normalização. Por conseguinte, os princípios contábeis, geralmente, não respondiam muito bem às 
Contabilidade Rural e de Custos aplicada à atividade leiteira: um estudo de caso em uma propriedade rural do Oeste de Santa Catarina

Cristian Bau Dal Magro, Mara Vogt, Larissa Degenhart, Leila Chaves Cunha, Fabricia Silva da Rosa

características particulares de negócios agrícolas e às necessidades de informação dos agricultores e suas partes interessadas.

Também há procura externa de informações contábeis para as atividades agrícolas, as quais são úteis para o desenvolvimento competitivo da agricultura familiar. $\mathrm{Na}$ época, os autores comentaram que o baixo envolvimento dos agricultores com a contabilidade estaria relacionado com a pouca adaptabilidade e difícil aplicação das regras contábeis na atividade agrícola (ARGILÉS e SLOF, 2001).

Em 2009, no Brasil, para sanar as deficiências apontadas e oferecer um padrão contábil útil e de fácil aplicabilidade pelos produtores rurais, emergiu o CPC 29, que abrange o ativo biológico e o produto agrícola. O CPC 29 estabeleceu o tratamento contábil e as respectivas divulgações relacionados aos ativos biológicos e aos produtos agrícolas. Evidencia que a atividade agrícola é o gerenciamento da transformação biológica e da colheita de ativos biológicos para venda ou para conversão em produtos agrícolas ou em ativos biológicos adicionais. Já a produção agrícola é o produto colhido de ativo biológico da entidade (CPC 29, 2009).

\subsection{Gestão Pecuária Leiteira}

As mudanças que vêm ocorrendo na gestão leiteira do Brasil, segundo Corrêa (2003), apresentam a necessidade de mudar as concepções sobre a gestão, com vistas a romper o conservadorismo, pois, conforme a Lei $n^{0}$ 11.326/2006, considera-se agricultor familiar e empreendedor familiar rural aquele que pratica atividades no meio rural, atendendo alguns requisitos, como utilizar mão de obra familiar nas atividades econômicas da propriedade, possuir renda familiar originada de atividades vinculadas ao estabelecimento ou empreendimento e, ainda, dirigir as atividades com sua família. Desse modo, como as propriedades rurais são gerenciadas, em sua maioria, pelas próprias famílias, gerenciar de forma adequada essa atividade é um desafio para a geração de renda, de empregos e a oportunidade do desenvolvimento sustentável, sendo que os sistemas de gestão da pecuária leiteira existentes carecem de aplicabilidade. 
Contabilidade Rural e de Custos aplicada à atividade leiteira: um estudo de caso em uma propriedade rural do Oeste de Santa Catarina Cristian Bau Dal Magro, Mara Vogt, Larissa Degenhart, Leila Chaves Cunha, Fabricia Silva da Rosa

Segundo Marion e Segatti (2006), analisar e propor um sistema de gestão de planejamento e de custos agropecuários para pequenas propriedades rurais, na cadeia produtiva do leite, favorece o produtor frente ao cenário econômico atual, pois destaca sua contribuição para a mão de obra e, consequentemente, para a renda. A pecuária leiteira passa por significativas mudanças, e o agronegócio vem sofrendo com a adoção de um modelo de gestão mais eficiente, sendo que o processo produtivo tem sido fundamental para todos os setores deste setor agropecuário (LOPES, 2007).

Diante de um cenário com declínio dos preços e limitado poder de negociação no mercado, o produtor necessita administrar o que é possível, adotando estratégias para tornar seu produto competitivo, encontrando indicadores técnicos e econômicos que permitam a utilização da gestão de custos como um instrumento competitivo na pecuária leiteira, alocando, dessa forma, corretamente os recursos (LOPES e REIS; YAMAGUCHI, 2007). Conforme Mendes e Teixeira (2009), para que se expandam os sistemas de gestão na pecuária, é preciso que se invista na formação dos produtores e não somente nos sistemas, a fim de que tenham noções de administração; além disso, os sistemas devem ser simples para facilitar a interpretação dos relatórios.

Segundo Dal Magro et al. (2013), a atividade rural apresenta um risco maior que as demais atividades devido às suas especificidades, sendo que, dentre os riscos aos quais estão sujeitas, encontram-se as variações climáticas. Além disso, destacam que, no setor agrícola, a atividade leiteira está entre as mais predominantes e rentáveis. Desse modo, Argilés e Slof (2001) confirmam que os agricultores que utilizam sistemas de registros formais, no longo do tempo, melhoram sua capacidade de utilizar as informações para melhoria do sistema produtivo e para competividade do negócio.

Ruberto et al. (2013) destacam que o setor agrícola enfrenta problemas relacionados à produtividade e aos preços que estão aliados à competitividade, sendo necessária a busca por alternativas que amenizem os impactos econômicos e financeiros. Para auxiliar na gestão desses produtores, é possível utilizar metodologias de custos para analisar e gerenciar os gastos, pois uma análise contábil estruturada auxilia o produtor na tomada de decisões, para que este possa obter maior produtividade e melhor resultado financeiro e econômico. 
Contabilidade Rural e de Custos aplicada à atividade leiteira: um estudo de caso em uma propriedade rural do Oeste de Santa Catarina Cristian Bau Dal Magro, Mara Vogt, Larissa Degenhart, Leila Chaves Cunha, Fabricia Silva da Rosa

Contudo, Novo et al. (2013) ressaltam que, no Brasil, o uso do solo e as mudanças promovidas pelas cadeias agrícolas exigem a busca de formas alternativas de produção para a agricultura, sendo que a heterogeneidade dos sistemas de produção de leite depende da combinação dos fatores de produção e aspectos sociais resultantes da alocação dos recursos.

Conforme Macdonald et al. (2007), as grandes empresas leiteiras geram retornos que, muitas vezes, excedem os custos totais. Por outro lado, as menores propriedades leiteiras geralmente incorrem em perdas econômicas; no entanto, algumas são rentáveis, e outras continuam a ganhar o suficiente para permanecerem em atividade. Para tanto, percebe-se a importância da contabilidade rural e de custos para o processo de gestão da atividade leiteira, pois os pequenos proprietários poderão se fortalecer cada vez mais, usufruindo da contabilidade para melhorar a gestão e, consequentemente, seu desenvolvimento.

Argilés e Slof (2001) comentam que o baixo nível de sofisticação gerencial, a falta de meios econômicos do setor e a adequação limitada dos princípios contábeis levaram à relutância dos agricultores na preparação de relatórios contábeis e a utilizar informações gerenciais em melhor proporção que as dos agentes de outros setores econômicos. Dessa forma, acredita-se que a contabilidade pode melhorar a gestão da exploração rural e levar a um melhor desempenho agrícola. Este estudo contribui com tal evidência, ao explorar a contribuição das informações gerenciais (contabilidade rural e de custo) para melhorar a gestão agrícola, sob o prisma de uma região brasileira.

\subsection{Estudos Relacionados}

Os estudos sobre a contribuição da contabilidade rural e de custos para a melhoria na gestão da atividade leiteira foram desenvolvidos por diversos autores e em diferentes contextos. Para tanto, Costa et al. (2013) analisaram os custos a partir da cadeia de valor do leite e derivados. Os resultados demonstraram que a unidade estudada ainda apresenta um sistema de custeamento bastante rudimentar e com prejuízo médio de $\mathrm{R} \$ 0,08$ por cada litro de leite vendido, evidenciando a necessidade 
Contabilidade Rural e de Custos aplicada à atividade leiteira: um estudo de caso em uma propriedade rural do Oeste de Santa Catarina Cristian Bau Dal Magro, Mara Vogt, Larissa Degenhart, Leila Chaves Cunha, Fabricia Silva da Rosa

da introdução de um sistema de custeamento mais eficiente, para controlar de forma mais eficaz as receitas e despesas.

Nascimento et al. (2013) investigaram sete produtos de seis vinícolas localizadas no Vale do São Francisco, analisando se as decisões tomadas, baseadas no Custeio Alvo, agregam valor econômico às empresas. Concluíram que há a necessidade de ajuste do modelo tradicional de Custeio Alvo, incorporando o custo da oportunidade dos fundos investidos.

Kruger et al. (2013) identificaram características da utilização das técnicas contábeis em propriedades rurais. Os resultados demonstram que $61 \%$ dos produtores rurais entrevistados não separam seus gastos particulares dos gastos com as atividades rurais e $45 \%$ destes não fazem nenhum tipo de controle ou anotações. Os achados indicam que $56 \%$ têm o preço dos produtos comercializados, estes que são definidos pelas empresas compradoras. Os objetivos e as finalidades da contabilidade são desconhecidos para $48 \%$ dos pesquisados.

Ruberto et al. (2013) objetivaram auxiliar o processo de gestão das propriedades rurais a partir da utilização da gestão de custos e da ferramenta matemática de programação linear. Os resultados demonstraram que a utilização das simulações realizadas com os modelos matemáticos e a utilização eficaz dos recursos disponíveis na propriedade poderia otimizar a produção, maximizar o lucro e a margem de contribuição.

Já o estudo de Novo et al. (2013) analisou a viabilidade técnica e econômica da atividade leiteira de pequenos agricultores por meio de um programa. Dessa forma, os agricultores que aderiram ao programa aumentaram a produção leiteira, e para os que não aderiram, a produção ficou reduzida em $8 \%$. Para tanto, verificaram que a produção leiteira intensiva foi uma oportunidade interessante para a maioria dos pequenos agricultores para agregar valor à produção local e criar maior renda por área e por unidade de trabalho. 
Contabilidade Rural e de Custos aplicada à atividade leiteira: um estudo de caso em uma propriedade rural do Oeste de Santa Catarina Cristian Bau Dal Magro, Mara Vogt, Larissa Degenhart, Leila Chaves Cunha, Fabricia Silva da Rosa

\section{PROCEDIMENTOS METODOLÓGICOS}

O presente estudo é caracterizado como uma pesquisa exploratória, documental e quantitativa, realizada por meio de um estudo de caso em uma propriedade leiteira localizada na região Oeste do Estado de Santa Catarina.

Para a coleta de dados, foram empregadas algumas técnicas. Inicialmente, foi utilizada a entrevista não estruturada, aplicada aos empresários rurais, com o intuito de obter informações gerais sobre a atividade leiteira e a propriedade rural em estudo. Em seguida, foi utilizada a observação não participante para absorver informações gerais dos processos produtivos e operacionais da atividade rural, sendo que o processo de observação não participante perdurou ao longo de um ano.

Por fim, foi utilizada a pesquisa documental para levantar o patrimônio utilizado para o desenvolvimento da atividade leiteira na propriedade rural em estudo. Além disso, por meio de informações obtidas junto aos proprietários e extraídas das notas fiscais de entradas e saídas, foi realizado um acompanhamento no período que compreendeu janeiro de 2013 a dezembro do mesmo ano, no intuito de efetuar o levantamento das receitas, custos e despesas que envolvem a atividade. A escolha da propriedade rural foi por acessibilidade, e a visita para a coleta dos dados foi realizada quinzenalmente.

Diante do exposto, foram seguidos os seguintes procedimentos para a coleta das informações que compreenderam a elaboração do sistema de contabilidade rural e de custos, aplicável à atividade rural: (a) levantamento da área de terra utilizada para a atividade; (b) cálculo do descarte de matrizes; (c) levantamento do número de animais que compõem o plantel da atividade leiteira; (d) levantamento dos custos e da produção de silagem e pastagem; (e) levantamento do preço de venda do leite; (f) levantamento da produtividade da atividade; e (g) levantamento dos custos variáveis e fixos. $\mathrm{Na}$ sequência, apresentam-se essas etapas mais detalhadamente na análise dos dados. 
Contabilidade Rural e de Custos aplicada à atividade leiteira: um estudo de caso em uma propriedade rural do Oeste de Santa Catarina Cristian Bau Dal Magro, Mara Vogt, Larissa Degenhart, Leila Chaves Cunha, Fabricia Silva da Rosa

\section{ANÁLISE DOS DADOS}

Dentre as atividades econômicas desenvolvidas pela sociedade, o setor agrícola tem demonstrado um elevado risco diante da volatilidade do mercado e das potenciais catástrofes ambientais. Desse modo, se faz necessário estabelecer mecanismos que auxiliem na melhoria da competividade do setor; portanto, este estudo busca contribuir com a demonstração da geração de informação gerencial aos pequenos produtores rurais.

A atividade leiteira foi escolhida pela sua importância para a economia mundial e predominância econômica em detrimento das demais atividades exercidas na propriedade rural em estudo. Neste caso, o custo da atividade leiteira será estimado com base no valor do custo total das atividades relacionadas à pecuária. Esse valor é composto pelos custos de produção do leite e os custos de criação dos animais de reposição, deduzindo-se o valor dos animais descartados para cálculo do custo de produção do leite (LOPES, 2006).

O levantamento dos dados foi realizado em uma propriedade agrícola familiar de médio porte, localizada no Oeste de Santa Catarina. A empresa rural, foco do estudo, está no mercado há aproximadamente quinze anos. A família que administra a propriedade também desenvolve atividades rurais adicionais que incrementam a renda, mas são insignificantes em relação à atividade leiteira.

Primeiramente, foram obtidas como relacionadas ao exercício da atividade leiteira. Para tanto, verificou-se que a propriedade compreende um total de 12,80 hectares formados por área própria e arrendada. A superfície agrícola útil da propriedade é de 7,65 hectares. Em relação ao descarte das matrizes, observou-se um valor de $\mathrm{R} \$ 1.500,00$ por cabeça. Para a retribuição ao fator da terra, consideraram-se $3 \%$, e a retribuição aos outros fatores de capital foi de $6 \%$.

Além disso, foram obtidas informações relacionadas aos animais da atividade leiteira que fizeram parte do estudo, compreendendo a variação dos doze meses analisados. Na Tabela 1, apresenta-se o número de animais e a variação durante o período que compreende o estudo. 
Contabilidade Rural e de Custos aplicada à atividade leiteira: um estudo de caso em uma propriedade rural do Oeste de Santa Catarina Cristian Bau Dal Magro, Mara Vogt, Larissa Degenhart, Leila Chaves Cunha, Fabricia Silva da Rosa

Tabela 1 - Número de animais e a variação durante o período que compreende o estudo

\begin{tabular}{|c|c|c|c|c|c|c|c|c|c|}
\hline & $\begin{array}{l}\text { Vaca em } \\
\text { Lactação }\end{array}$ & $\begin{array}{l}\text { Vaca } \\
\text { Seca }\end{array}$ & Touro & $\begin{array}{l}\text { Novilha } 1 \\
\text { a } 2 \text { anos }\end{array}$ & $\begin{array}{c}\text { Novilha } \\
2 \text { a } 3 \\
\text { anos }\end{array}$ & $\begin{array}{c}\text { Macho } \\
1 \text { a } 2 \\
\text { anos }\end{array}$ & $\begin{array}{c}\text { Bezerr } \\
\text { a até } 1 \\
\text { ano }\end{array}$ & $\begin{array}{c}\text { Bezerr } \\
0 \text { até } 1 \\
\text { ano }\end{array}$ \\
\hline \multicolumn{2}{|c|}{$\mathrm{R} \$ / \mathrm{Cab}$} & $2.000,00$ & $1.700,00$ & $2.000,0$ & $1.500,00$ & $2.500,0$ & 400,00 & 250,00 & 100,00 \\
\hline Jan & Inic. & 16 & 7 & 1 & 2 & 4 & 0 & 8 & 3 \\
\hline \multirow{2}{*}{ Fev } & Inic. & 16 & 7 & 1 & 2 & 4 & 0 & 8 & 3 \\
\hline & Desc & 0 & (1) & 0 & 0 & 0 & 0 & 0 & 0 \\
\hline Mar & Inic. & 16 & 6 & 1 & 2 & 3 & 0 & 8 & 3 \\
\hline \multirow[b]{2}{*}{ Abr } & Inic. & 17 & 6 & 1 & 5 & 1 & 1 & 6 & 3 \\
\hline & Mort. & 0 & 0 & 0 & 0 & 0 & 0 & 0 & (2) \\
\hline \multirow{3}{*}{ Mai } & Inic. & 21 & 4 & 1 & 5 & 1 & 1 & 4 & 1 \\
\hline & Mort. & 0 & 0 & 0 & 0 & 0 & 0 & 0 & (3) \\
\hline & Nasc & 0 & 0 & 0 & 0 & 0 & 0 & 0 & 5 \\
\hline \multirow{2}{*}{ Jun } & Inic. & 23 & 3 & 1 & 7 & 0 & 1 & 3 & 2 \\
\hline & Nasc & 0 & 0 & 0 & 0 & 0 & 0 & 0 & 2 \\
\hline \multirow[b]{2}{*}{ Jul } & Inic. & 23 & 3 & 1 & 7 & 0 & 1 & 3 & 4 \\
\hline & Nasc & 0 & 0 & 0 & 0 & 0 & 0 & 0 & 1 \\
\hline \multirow{4}{*}{ Ago } & Inic. & 23 & 3 & 1 & 7 & 0 & 1 & 3 & 5 \\
\hline & Desc & (1) & 0 & 0 & 0 & 0 & 0 & 0 & 0 \\
\hline & Mort. & 0 & 0 & 0 & 0 & 0 & (1) & 0 & 0 \\
\hline & Nasc & 0 & 0 & 0 & 0 & 0 & 0 & 1 & 0 \\
\hline Set & Inic. & 22 & 3 & 1 & 7 & 0 & 0 & 4 & 5 \\
\hline Out & Inic. & 22 & 3 & 1 & 7 & 0 & 0 & 4 & 5 \\
\hline Nov & Inic. & 22 & 3 & 1 & 7 & 0 & 0 & 4 & 5 \\
\hline \multirow{2}{*}{ Dez } & Inic. & 18 & 7 & 1 & 7 & 0 & 0 & 4 & 5 \\
\hline & Nasc & 0 & 0 & 0 & 0 & 0 & 0 & 2 & 0 \\
\hline \multicolumn{2}{|c|}{ Final } & 18 & 7 & 1 & 7 & 0 & 0 & 6 & 5 \\
\hline
\end{tabular}

Legenda: Inic.- número de cabeças iniciais; Desc .- número de cabeças descartadas; Mort. - número de cabeças mortas; Nasc.- número de nascimentos.

Fonte: Dados da pesquisa

Verifica-se, na Tabela 1, que em janeiro havia, na propriedade, 16 vacas em lactação (produtoras de leite); 7 vacas secas; 1 touro; 2 novilhas de 1 a 2 anos; 4 novilhas de 2 a 3 anos; 8 bezerras de até 1 ano; e 3 bezerros de até 1 ano. No mês de fevereiro, houve variação no número de animais pelo descarte de 1 vaca seca. Já no mês de março, não ocorreram variações no número de animais. Em abril, morreram 2 bezerros de até 1 ano, sobrando apenas 1 bezerro de até 1 ano. Além disso, neste mesmo mês, ocorreram movimentações relacionadas às vacas em lactação, novilhas de 1 a 2 anos, novilhas de 2 a 3 anos e bezerras de até 1 ano. 
Contabilidade Rural e de Custos aplicada à atividade leiteira: um estudo de caso em uma propriedade rural do Oeste de Santa Catarina Cristian Bau Dal Magro, Mara Vogt, Larissa Degenhart, Leila Chaves Cunha, Fabricia Silva da Rosa

No mês de maio, nasceram 5 bezerros, contudo morreram 3, e assim sobraram 2 bezerros de até 1 ano para compor o período seguinte. Além disso, no mês de maio também foram observadas alterações nos animais que compreendem a lactação: vacas secas e bezerras de até 1 ano. Em junho, nasceram 2 bezerros e também houve realocação das vacas em lactação, vacas secas, novilhas de 1 a 2 anos e bezerras de até 1 ano. Ainda, em julho, houve o nascimento de 1 bezerro.

No mês de agosto, ocorreram os seguintes eventos: descarte de 1 vaca em lactação, morte de 1 macho de 1 a 2 anos e nascimento de 1 bezerra. Nos meses de setembro, outubro e novembro, não houve variações de animais que compreendem a atividade leiteira na propriedade em estudo. Por fim, no mês de dezembro, nasceram 2 bezerras. Os dados relacionados ao número de animais e suas variações foram utilizados para o cálculo do lucro por vaca em lactação e a obtenção das receitas relacionadas à venda de animais em descarte.

Posteriormente, foram levantados os custos destinados à produção de silagem e pastagem de inverno, ambos utilizados para alimentação dos animais utilizados na atividade leiteira. A Tabela 2 demonstra o levantamento dos custos para a produção da silagem e da pastagem de inverno. 
Contabilidade Rural e de Custos aplicada à atividade leiteira: um estudo de caso em uma propriedade rural do Oeste de Santa Catarina Cristian Bau Dal Magro, Mara Vogt, Larissa Degenhart, Leila Chaves Cunha, Fabricia Silva da Rosa

Tabela 2 - Levantamento dos custos para produção de silagem e pastagem de inverno

\begin{tabular}{|c|c|c|}
\hline Produção & Quant. (Kg) & Perdas (\%) \\
\hline Silagem & 150.000 & 2 \\
\hline Pastagem de inverno & 195.000 & 15 \\
\hline \multicolumn{3}{|c|}{ Despesas Produção da Silagem } \\
\hline Despesas & Quantidade & Valor $(\mathbf{R} \$)$ \\
\hline \multicolumn{3}{|l|}{ Preparo do Solo: } \\
\hline Trator & 4,0 & 320,00 \\
\hline \multicolumn{2}{|c|}{ Total } & 320,00 \\
\hline \multicolumn{3}{|l|}{ Insumos: } \\
\hline Semente de milho & 4,0 & 500,00 \\
\hline Adubo Químico & 20,0 & $1.400,00$ \\
\hline Ureia & 10,0 & 600,00 \\
\hline Adubo de aviário & 15,0 & 800,00 \\
\hline \multicolumn{2}{|c|}{ Total } & $3.300,00$ \\
\hline \multicolumn{3}{|l|}{ Tratos Culturais: } \\
\hline Dessecante & 7,0 & 140,00 \\
\hline Veneno & 15,0 & 195,00 \\
\hline \multicolumn{2}{|c|}{ Total } & 335,00 \\
\hline \multicolumn{3}{|l|}{ Colheita: } \\
\hline Serviço de silagem & 13,0 & 520,00 \\
\hline \multicolumn{2}{|l|}{ Total } & 520,00 \\
\hline \multicolumn{2}{|l|}{ Total geral } & $4.475,00$ \\
\hline \multicolumn{2}{|l|}{ Custo Médio $(\mathrm{R} \$ / \mathrm{Kg})$} & 0,0304 \\
\hline \multicolumn{3}{|c|}{ Despesas Produção da Pastagem de Inverno } \\
\hline Despesas & Quantidade & Valor $(\mathbf{R} \$)$ \\
\hline \multicolumn{3}{|l|}{ Preparo do Solo: } \\
\hline Trator & & 300,00 \\
\hline \multicolumn{2}{|c|}{ Total } & 300,00 \\
\hline \multicolumn{3}{|l|}{ Insumos: } \\
\hline Semente de aveia & 600,0 & 480,00 \\
\hline Semente de azevém & 100,0 & 250,00 \\
\hline Ureia & 250,0 & 250,00 \\
\hline \multicolumn{2}{|l|}{ Total } & 980,00 \\
\hline \multicolumn{2}{|l|}{ Total geral } & $1.280,00$ \\
\hline \multicolumn{2}{|l|}{ Custo Médio $(\mathrm{R} \$ / \mathrm{Kg})$} & 0,0077 \\
\hline
\end{tabular}

Legenda: No custo médio do $\mathrm{Kg}$ da silagem, foi considerada a perda de $2 \%$ e, no custo médio do $\mathrm{Kg}$ da pastagem de inverno, foi considerada a perda de $15 \%$.

Fonte: Dados da pesquisa

Observa-se na Tabela 2 que, para a alimentação dos animais, foi preciso uma produção anual de $150.000 \mathrm{~kg}$ de silagem e $195.000 \mathrm{~kg}$ de pastagem de inverno, considerando-se uma perda estimada de $2 \%$ na produção da silagem e de $15 \%$ na produção da pastagem de inverno. Para a produção da silagem, foi estimado o valor total de $R \$ 4.475,00$ e um custo médio por $\mathrm{kg}$ de $\mathrm{R} \$ 0,0304$. Já para a produção da 
Contabilidade Rural e de Custos aplicada à atividade leiteira: um estudo de caso em uma propriedade rural do Oeste de Santa Catarina Cristian Bau Dal Magro, Mara Vogt, Larissa Degenhart, Leila Chaves Cunha, Fabricia Silva da Rosa

pastagem de inverno, foi estimado o valor total de $\mathrm{R} \$ 1.280,00$ e um custo médio por $\mathrm{kg}$ de $R \$ 0,0077$.

Além do levantamento dos custos de produção da alimentação produzida na propriedade, foi verificada a produção mensal das vacas em lactação, o preço mensal do leite vendido, a produtividade de litros de leite por hectare, de litros de leite por vaca, de litros de leite por vaca em lactação, o percentual de vacas total em relação ao total do rebanho e percentual de vacas em lactação em relação ao total de vacas. A Tabela 3 mostra os indicadores técnicos da propriedade em relação à atividade leiteira.

Tabela 3 - Indicadores técnicos em relação à atividade leiteira

\begin{tabular}{|c|c|c|c|c|c|c|c|}
\hline & $\begin{array}{c}\text { Produção } \\
\text { Total (It) }\end{array}$ & $\begin{array}{c}\text { Preço } \\
\text { Leite } \\
\text { (R\$/It) }\end{array}$ & $\begin{array}{l}\text { Produt. } \\
\text { (It/ha) }\end{array}$ & $\begin{array}{c}\text { Produt. } \\
\text { (It/vaca } \\
\text { total) }\end{array}$ & $\begin{array}{c}\text { Produt. } \\
\text { (Lt/vaca } \\
\text { lact.) }\end{array}$ & $\begin{array}{c}\text { \% vacas } \\
\text { totais/total } \\
\text { do } \\
\text { rebanho }\end{array}$ & $\begin{array}{c}\text { \% vacas } \\
\text { lactação/ } \\
\text { total vacas }\end{array}$ \\
\hline Jan & 6.100 & 0,54 & $1.129,53$ & 265,22 & 381,25 & $56 \%$ & $70 \%$ \\
\hline Fev & 4.675 & 0,53 & 865,74 & 203,26 & 292,19 & $56 \%$ & $70 \%$ \\
\hline Mar & 4.917 & 0,57 & 910,56 & 223,50 & 307,31 & $55 \%$ & $73 \%$ \\
\hline Abr & 6.450 & 0,65 & $1.194,44$ & 280,43 & 379,41 & $58 \%$ & $74 \%$ \\
\hline Mai & 7.385 & 0,65 & $1.367,59$ & 295,40 & 351,67 & $66 \%$ & $84 \%$ \\
\hline Jun & 8.860 & 0,62 & $1.640,74$ & 340,77 & 385,22 & $65 \%$ & $88 \%$ \\
\hline Jul & 11.012 & 0,675 & $2.039,26$ & 423,54 & 478,78 & $62 \%$ & $88 \%$ \\
\hline Ago & 10.185 & 0,62 & $1.886,11$ & 391,73 & 442,83 & $60 \%$ & $88 \%$ \\
\hline Set & 9.436 & 0,55 & $1.747,41$ & 377,44 & 428,91 & $60 \%$ & $88 \%$ \\
\hline Out & 9.916 & 0,59 & $1.836,30$ & 396,64 & 450,73 & $60 \%$ & $88 \%$ \\
\hline Nov & 10.761 & 0,58 & $1.992,78$ & 430,44 & 489,14 & $60 \%$ & $88 \%$ \\
\hline Dez & 9.228 & 0,63 & $1.708,89$ & 369,12 & 512,67 & $60 \%$ & $72 \%$ \\
\hline Total & 98.925 & & $18.319,44$ & $3.997,49$ & $4.900,09$ & \multirow{2}{*}{$60 \%$} & \multirow{2}{*}{$81 \%$} \\
\hline Média & $8.243,75$ & 0,60 & $1.526,62$ & 333,12 & 408,34 & & \\
\hline
\end{tabular}

Legenda: Lt - Litros; há - Hectares; lact. - Lactação; Produtiv. - Produtividade Fonte: Dados da pesquisa

Observa-se, na Tabela 3, que o mês de julho apresentou a maior produtividade, com uma produção de 11.012 litros de leite. Os meses de fevereiro e março apresentaram a menor produtividade, com 4.675 e 4.917 litros de leite, respectivamente. A produtividade de leite por hectare no mês de julho foi de 2.039,26 litros, e a produtividade de leite por vaca em lactação foi de 478,78 litros. O percentual médio de vacas em lactação em relação ao número de vacas total foi de $81 \%$. 
Contabilidade Rural e de Custos aplicada à atividade leiteira: um estudo de caso em uma propriedade rural do Oeste de Santa Catarina Cristian Bau Dal Magro, Mara Vogt, Larissa Degenhart, Leila Chaves Cunha, Fabricia Silva da Rosa

Destaca-se que, no período que compreendeu os meses de maio a dezembro, houve maior proporção de vacas que apresentaram alta produtividade. Em relação ao rebanho total, o número de vacas representa, em média, $60 \%$ para o período analisado. A produção média mensal de leite para o ano foi de 8.243,75 litros; a produtividade de leite média mensal por hectare no ano foi de 1.526,62 litros; e a produtividade de leite média mensal por vaca em lactação foi de 408,34 litros.

Com base nas estimativas da produção mensal de leite, com o consumo de leite na propriedade e com a venda de animais em descarte, foi possível calcular as receitas mensais. A Tabela 4 demonstra as receitas da atividade leiteira para o ano.

Tabela 4 - Receitas da atividade leiteira

\begin{tabular}{|c|c|c|c|c|c|c|}
\hline Descrição & Jan. & Fev. & Mar. & Abr. & Maio & Jun. \\
\hline Receita Leite cota & $3.172,00$ & $2.448,00$ & $2.730,00$ & $4.046,25$ & $4.683,25$ & $5.418,80$ \\
\hline $\begin{array}{c}\text { Receita Leite } \\
\text { Consumido }\end{array}$ & 28,00 & 27,00 & 17,00 & 29,25 & 19,50 & 18,75 \\
\hline Venda de animais & 0,00 & 0,00 & 400,00 & 0,00 & 0,00 & 0,00 \\
\hline Leite dado a Bezerros & 97,20 & 49,50 & 104,00 & 117,00 & 97,50 & 56,25 \\
\hline Total Mês & $\mathbf{3 . 2 9 7 , 2 0}$ & $\mathbf{2 . 5 2 4 , 5 0}$ & $\mathbf{3 . 2 5 1 , 0 0}$ & $\mathbf{4 . 1 9 2 , 5 0}$ & $\mathbf{4 . 8 0 0 , 2 5}$ & $\mathbf{5 . 4 9 3 , 8 0}$ \\
\hline Descrição & Jul. & Ago. & Set. & Out. & Nov. & Dez. \\
\hline Receita Leite cota & $7.156,94$ & $6.093,40$ & $5.107,30$ & $5.770,79$ & $6.171,78$ & $5.775,84$ \\
\hline $\begin{array}{c}\text { Receita Leite } \\
\text { Consumido }\end{array}$ & 20,25 & 27,00 & 30,00 & 26,55 & 34,80 & 37,80 \\
\hline Venda de animais & 0,00 & 0,00 & 0,00 & 0,00 & 0,00 & 0,00 \\
\hline Leite dado a Bezerros & 202,50 & 90,00 & 45,00 & 53,10 & 34,80 & 0,00 \\
\hline Total Mês & $\mathbf{7 . 3 7 9 , 6 9}$ & $\mathbf{6 . 1 2 0 , 4 0}$ & $\mathbf{5 . 1 8 2 , 3 0}$ & $\mathbf{5 . 8 5 0 , 4 4}$ & $\mathbf{6 . 2 4 1 , 3 8}$ & $\mathbf{5 . 8 1 3 , 6 4}$ \\
\hline \multicolumn{7}{|c|}{ Total de Receitas do período } \\
\hline \multicolumn{7}{|c|}{ Média de Receitas do período } \\
\hline
\end{tabular}

Fonte: Dados da pesquisa

Verifica-se, na Tabela 4, que o mês de julho apresentou maior receita total, com $\mathrm{R} \$ 7.379,69$. A receita total dos doze meses foi de $\mathrm{R} \$ 60.237,10$ e a receita média do período em estudo foi de $\mathrm{R} \$ 5.019,76$. Para determinar a lucratividade da atividade, foi preciso elaborar um levantamento dos custos variáveis para a atividade leiteira. A Tabela 5 mostra os custos variáveis da atividade leiteira. 
Contabilidade Rural e de Custos aplicada à atividade leiteira: um estudo de caso em uma propriedade rural do Oeste de Santa Catarina Cristian Bau Dal Magro, Mara Vogt, Larissa Degenhart, Leila Chaves Cunha, Fabricia Silva da Rosa

Tabela 5 - Custos variáveis da atividade leiteira

\begin{tabular}{|c|c|c|c|c|c|c|}
\hline Descrição & Jan. & Fev. & Mar. & Abr. & Maio & Jun. \\
\hline Mão de obra eventual & 20,00 & 100,00 & 0,00 & 0,00 & 0,00 & 0,00 \\
\hline Silagem & 197,87 & 219,18 & 273,98 & 410,97 & 379,92 & 401,84 \\
\hline Pastagem de inverno & 0,00 & 0,00 & 0,00 & 157,54 & 157,54 & 157,54 \\
\hline Ração vacas lactação & 954,00 & 780,00 & $1.053,00$ & $1.120,00$ & $1.416,00$ & $1.446,50$ \\
\hline Ração bezerras & 0,00 & 17,50 & 65,00 & 96,00 & 96,88 & 0,00 \\
\hline Leite dado a bezerros & 97,20 & 49,50 & 104,00 & 117,00 & 97,50 & 56,25 \\
\hline Sal comum & 8,00 & 8,00 & 0,00 & 9,00 & 9,00 & 9,00 \\
\hline Sal Mineral & 45,00 & 28,00 & 28,00 & 23,50 & 47,50 & 42,50 \\
\hline Milho (rolão ou grãos) & 0,00 & 0,00 & 0,00 & 80,00 & 80,00 & 0,00 \\
\hline Sêmen & 40,00 & 100,00 & 0,00 & 0,00 & 0,00 & 0,00 \\
\hline Adubo & 97,00 & 0,00 & 250,00 & 0,00 & 120,00 & 523,00 \\
\hline Vacinas & 0,00 & 0,00 & 0,00 & 7,00 & 20,00 & 0,00 \\
\hline Medicamentos & 45,00 & 0,00 & 0,00 & 10,40 & 176,00 & 28,50 \\
\hline Lubrificantes & 17,00 & 0,00 & 0,00 & 0,00 & 0,00 & 0,00 \\
\hline Material higiene/limpeza & 0,00 & 11,25 & 0,00 & 0,00 & 25,00 & 0,00 \\
\hline Consertos máq./equip. & 40,00 & 0,00 & 0,00 & 0,00 & 0,00 & 0,00 \\
\hline INSS (Funrural) & 72,95 & 56,30 & 62,79 & 95,00 & 107,71 & 128,00 \\
\hline Energia elétrica & 100,00 & 110,00 & 110,00 & 52,50 & 57,50 & 60,00 \\
\hline Aluguel de máquinas & 0,00 & 0,00 & 0,00 & 0,00 & 0,00 & 0,00 \\
\hline Outras desp. Variáveis & 0,00 & 0,00 & 0,00 & 820,00 & 0,00 & 10,00 \\
\hline Total Custo variáveis mês & $1.734,02$ & $1.479,73$ & $1.946,77$ & $2.998,91$ & $2.790,55$ & $2.863,13$ \\
\hline Descrição & Jul. & Ago. & Set. & Out. & Nov. & Dez. \\
\hline Mão de obra eventual & 0,00 & 0,00 & 0,00 & 40,00 & 0,00 & 0,00 \\
\hline Silagem & 185,70 & 0,00 & 298,33 & 328,78 & 328,78 & 0,00 \\
\hline Pastagem de inverno & 157,54 & 0,00 & 0,00 & 0,00 & 0,00 & 0,00 \\
\hline Ração vacas lactação & $1.402,00$ & $1.326,00$ & $1.635,00$ & $1.560,00$ & $1.636,00$ & $1.242,00$ \\
\hline Ração bezerras & 110,00 & 115,00 & 120,00 & 125,19 & 125,00 & 83,40 \\
\hline Leite dado a bezerros & 202,50 & 90,00 & 45,00 & 53,10 & 34,80 & 0,00 \\
\hline Sal comum & 0,00 & 9,00 & 9,00 & 0,00 & 0,00 & 0,00 \\
\hline Sal Mineral & 42,50 & 42,50 & 42,70 & 85,09 & 41,70 & 41,75 \\
\hline Milho (rolão ou grãos) & 0,00 & 0,00 & 0,00 & 0,00 & 0,00 & 0,00 \\
\hline Sêmen & 0,00 & 0,00 & 0,00 & 0,00 & 0,00 & 0,00 \\
\hline Adubo & 0,00 & 0,00 & 0,00 & 0,00 & 0,00 & 0,00 \\
\hline Vacinas & 0,00 & 0,00 & 0,00 & 0,00 & 0,00 & 0,00 \\
\hline Medicamentos & 54,00 & 52,00 & 62,00 & 110,00 & 32,00 & 130,00 \\
\hline Lubrificantes & 7,50 & 0,00 & 0,00 & 0,00 & 0,00 & 0,00 \\
\hline Material higiene/limpeza & 0,00 & 0,00 & 0,00 & 0,00 & 0,00 & 0,00 \\
\hline Consertos máq./equip. & 0,00 & 0,00 & 0,00 & 0,00 & 0,00 & 0,00 \\
\hline INSS (Funrural) & 164,60 & 155,00 & 117,46 & 132,72 & 177,77 & 169,00 \\
\hline Energia Elétrica & 50,00 & 70,00 & 70,00 & 54,00 & 70,00 & 70,00 \\
\hline Aluguel de Máquinas & 0,00 & 0,00 & 120,00 & 520,00 & 186,00 & 0,00 \\
\hline Outras desp. Variáveis & 124,50 & 537,80 & 37,75 & 196,00 & $1.100,00$ & 28,00 \\
\hline Total Custo variáveis mês & $2.500,84$ & $2.397,30$ & $2.557,24$ & $3.204,88$ & $3.732,05$ & $1.764,15$ \\
\hline \multicolumn{6}{|c|}{ Total de Custos variáveis período } & $29.969,56$ \\
\hline \multicolumn{6}{|c|}{ Média de Custos variáveis período } & $2.497,46$ \\
\hline
\end{tabular}

Fonte: Dados da pesquisa 
Contabilidade Rural e de Custos aplicada à atividade leiteira: um estudo de caso em uma propriedade rural do Oeste de Santa Catarina Cristian Bau Dal Magro, Mara Vogt, Larissa Degenhart, Leila Chaves Cunha, Fabricia Silva da Rosa

Verifica-se que os custos variáveis para a atividade leiteira compreenderam a mão de obra eventual, os custos com a silagem consumida, ambos calculados com base no custo médio apresentado na Tabela 2, de acordo com a quantidade de $\mathrm{kg}$ consumida pelos animais. O mesmo ocorre com a pastagem de inverno.

Além disso, os custos variáveis são compostos pela ração consumida, leite consumido, sal comum, sal mineral, milho em grão, sêmen para inseminação das vacas para reprodução de bezerros, adubo, vacinas, medicamentos, lubrificantes, material de higiene e limpeza, conserto de máquinas e equipamentos, impostos (INSS/Funrural), energia elétrica, aluguel de máquinas e outras despesas.

Observa-se, na Tabela 5, que o maior custo variável mensal na atividade leiteira esteve relacionado com a ração consumida pelas vacas em lactação. Em seguida, podem ser mencionados os custos envolvendo a silagem consumida. De modo geral, pode-se inferir que os custos com alimentação dos animais são os mais representativos na atividade leiteira.

Os meses que apresentaram maiores custos variáveis foram dezembro, com $R \$$ 3.732,05; novembro, com $R \$ 3.204,88$; abril, com $R \$ 2.998,91$; e junho com 2.863,13. Além disso, verificou-se que os custos variáveis, compreendidos durante os doze meses, totalizaram o valor de $\mathrm{R} \$ 29.969,56$, e a média mensal foi estimada no valor de $\mathrm{R} \$ 2.497,46$. Por fim, são demonstrados os custos fixos na Tabela 6. 
Contabilidade Rural e de Custos aplicada à atividade leiteira: um estudo de caso em uma propriedade rural do Oeste de Santa Catarina Cristian Bau Dal Magro, Mara Vogt, Larissa Degenhart, Leila Chaves Cunha, Fabricia Silva da Rosa

Tabela 6 - Custos fixos da atividade leiteira

\begin{tabular}{|c|c|c|c|c|c|c|}
\hline Descrição & Jan. & Fev. & Mar. & Abr. & Maio & Jun. \\
\hline \multicolumn{7}{|l|}{ Depreciações } \\
\hline Benfeitorias & 45,47 & 45,47 & 45,47 & 45,47 & 45,47 & 45,47 \\
\hline Máquinas/Equipam. & 187,21 & 187,21 & 187,21 & 187,21 & 187,21 & 187,21 \\
\hline Pastagens & 5,27 & 5,27 & 5,27 & 5,27 & 5,27 & 5,27 \\
\hline \multicolumn{7}{|l|}{ Remuneração Capital } \\
\hline Circulante & 104,04 & 88,78 & 116,81 & 179,93 & 167,43 & 171,79 \\
\hline Benfeitorias & 28,30 & 28,30 & 28,30 & 28,30 & 28,30 & 28,30 \\
\hline Máquinas/Equipam. & 42,50 & 42,50 & 42,50 & 42,50 & 42,50 & 42,50 \\
\hline Terra Nua & 114,75 & 114,75 & 114,75 & 114,75 & 114,75 & 114,75 \\
\hline Pastagens perenes & 0,90 & 0,90 & 0,90 & 0,90 & 0,90 & 0,90 \\
\hline Animais Produção & 219,50 & 219,50 & & 244,00 & 245,50 & \\
\hline Total Custos fixos mês & 747,96 & 732,70 & 541,23 & 848,36 & 837,35 & 596,21 \\
\hline Descrição & Jul. & Ago. & Set. & Out. & Nov. & Dez. \\
\hline \multicolumn{7}{|l|}{ Depreciações } \\
\hline Benfeitorias & 45,47 & 45,47 & 45,47 & 45,47 & 45,47 & 45,47 \\
\hline Máquinas/Equipam. & 187,21 & 187,21 & 187,21 & 187,21 & 187,21 & 187,21 \\
\hline Pastagens & 5,27 & 5,27 & 5,27 & 5,27 & 5,27 & 5,27 \\
\hline \multicolumn{7}{|l|}{ Remuneração Capital } \\
\hline Circulante & 150,05 & 143,84 & 153,43 & 192,29 & 223,92 & 105,85 \\
\hline Benfeitorias & 28,30 & 28,30 & 28,30 & 28,30 & 28,30 & 28,30 \\
\hline Máquinas/Equipam. & 42,50 & 42,50 & 42,50 & 42,50 & 42,50 & 42,50 \\
\hline Terra Nua & 114,75 & 114,75 & 114,75 & 114,75 & 114,75 & 114,75 \\
\hline Pastagens perenes & 0,90 & 0,90 & 0,90 & 0,90 & 0,90 & 0,90 \\
\hline Animais Produção & 239,50 & & & & & \\
\hline Total Custos fixos mês & 813,97 & 568,26 & 577,86 & 616,71 & 648,34 & 530,27 \\
\hline \multicolumn{6}{|c|}{ Total de Custos fixos período } & $8.059,22$ \\
\hline & Média d & stos fix & eríodo & & & 671,60 \\
\hline
\end{tabular}

Fonte: Dados da pesquisa

Verifica-se, na Tabela 6, que os custos fixos foram estimados pela depreciação de benfeitorias, máquinas/equipamentos e pastagens e, com base na remuneração do capital, que é composta por circulante, benfeitorias, máquinas/equipamentos, terra nua, pastagens perenes e animais em produção.

Os meses com maiores custos fixos foram: abril, com o valor de $R \$ 848,36$; maio, com o valor de $R \$ 837,35$; e julho, com o valor de $R \$ 813,97$. Os custos fixos para o período totalizaram $R \$ 8.059,22$ e, em média, os custos fixos mensais para o período foram de $\mathrm{R} \$ 671,60$. Com base nas estimativas apresentadas nas Tabelas 1, 2, 3, 4, 5 e 6, foi possível elaborar o cálculo de indicadores econômicos para a atividade leiteira, conforme demonstrado na Tabela 7. 
Contabilidade Rural e de Custos aplicada à atividade leiteira: um estudo de caso em uma propriedade rural do Oeste de Santa Catarina Cristian Bau Dal Magro, Mara Vogt, Larissa Degenhart, Leila Chaves Cunha, Fabricia Silva da Rosa

Tabela 7 - Indicadores econômicos da Atividade leiteira

\begin{tabular}{|c|c|c|c|c|c|c|c|c|c|}
\hline & \multicolumn{3}{|c|}{ Renda Bruta (R\$) } & \multicolumn{3}{|c|}{ Custo Variável (R\$) } & \multicolumn{3}{|c|}{ Custo Fixo (R\$) } \\
\hline & /ha & $/$ /t & Total & /ha & /It & Total & /ha & /It & Total \\
\hline Jan. & 341,68 & 0,54 & $3.297,20$ & 179,69 & 0,28 & $1.734,02$ & 77,51 & 0,13 & 747,97 \\
\hline Fev. & 261,61 & 0,54 & $2.524,50$ & 153,34 & 0,32 & $1.479,73$ & 75,93 & 0,15 & 732,71 \\
\hline Mar. & 336,89 & 0,66 & $3.251,00$ & 201,74 & 0,40 & $1.946,77$ & 56,08 & 0,10 & 541,23 \\
\hline Abr. & 434,46 & 0,65 & $4.192,50$ & 310,77 & 0,46 & $2.998,91$ & 87,91 & 0,14 & 848,35 \\
\hline Maio & 497,44 & 0,65 & $4.800,25$ & 289,18 & 0,38 & $2.790,55$ & 86,77 & 0,11 & 837,35 \\
\hline Jun. & 569,31 & 0,62 & $5.493,80$ & 296,70 & 0,32 & $2.863,13$ & 61,78 & 0,07 & 596,20 \\
\hline Jul. & 764,73 & 0,67 & $7.379,69$ & 259,15 & 0,23 & $2.500,84$ & 84,35 & 0,07 & 813,97 \\
\hline Ago. & 643,56 & 0,61 & $6.210,40$ & 248,42 & 0,24 & $2.397,30$ & 58,89 & 0,05 & 568,26 \\
\hline Set. & 537,03 & 0,55 & $5.182,30$ & 265,00 & 0,27 & $2.557,24$ & 59,88 & 0,06 & 577,86 \\
\hline Out. & 606,26 & 0,59 & $5.850,44$ & 332,11 & 0,32 & $3.204,88$ & 63,91 & 0,07 & 616,71 \\
\hline Nov. & 646,78 & 0,58 & $6.241,38$ & 386,74 & 0,35 & 2,05 & 67,19 & 0,06 & 648,34 \\
\hline Dez. & 602,45 & 0,63 & $5.813,64$ & 182,81 & 0,19 & $1.764,15$ & 54,95 & 0,06 & 530,27 \\
\hline $\begin{array}{l}\text { Total } \\
\text { anual }\end{array}$ & \multicolumn{2}{|c|}{$6.242,19$} & $60.237,10$ & \multicolumn{2}{|c|}{$3.105,65$} & $29.969,56$ & \multicolumn{2}{|c|}{835,15} & $8.059,22$ \\
\hline \multirow[t]{3}{*}{$\begin{array}{l}\text { Média } \\
\text { anual }\end{array}$} & 520,18 & 0,61 & $5.019,76$ & 258,80 & 0,30 & $2.497,46$ & 69,60 & 0,09 & 671,60 \\
\hline & \multicolumn{3}{|c|}{ Margem Bruta $(\mathbf{R} \$)$} & \multicolumn{3}{|c|}{ Lucro $(\mathbf{R} \$)$} & $\begin{array}{c}\text { Lucro/ } \\
\text { vaca }\end{array}$ & $\begin{array}{c}\% \\
\text { Lucr. }\end{array}$ & $\begin{array}{l}\text { Retorno } \\
\text { (lucr/Ct) }\end{array}$ \\
\hline & /ha & /It & Total & /ha & /It & Total & & & \\
\hline Jan. & 161,99 & 0,26 & $1.563,18$ & 84,48 & 0,13 & 815,21 & 35,44 & 24,72 & 0,33 \\
\hline Fev. & 108,27 & 0,22 & $1.044,77$ & 32,34 & 0,07 & 312,06 & 13,57 & 12,36 & 0,14 \\
\hline Mar. & 135,15 & 0,27 & $1.304,23$ & 79,07 & 0,16 & 763,00 & 34,68 & 23,46 & 0,31 \\
\hline Abr. & 123,69 & 0,19 & $1.193,59$ & 35,78 & 0,05 & 345,24 & 15,01 & 8,23 & 0,09 \\
\hline Maio & 208,26 & 0,27 & $2.009,70$ & 121,49 & 0,16 & $1.172,35$ & 46,89 & 24,42 & 0,32 \\
\hline Jun. & 272,61 & 0,30 & $2.630,67$ & 210,83 & 0,23 & $2.034,47$ & 78,25 & 37,03 & 0,59 \\
\hline Jul. & 505,58 & 0,44 & $4.878,85$ & 421,23 & 0,37 & $4.064,88$ & 156,34 & 55,08 & 1,23 \\
\hline Ago. & 395,14 & 0,37 & $3.813,10$ & 336,25 & 0,32 & $3.244,84$ & 124,80 & 52,24 & 1,09 \\
\hline Set. & 272,03 & 0,28 & $2.625,06$ & 212,15 & 0,22 & $2.047,20$ & 81,89 & 39,50 & 0,65 \\
\hline Out. & 274,15 & 0,27 & $2.645,56$ & 210,24 & 0,20 & $2.028,85$ & 81,15 & 34,67 & 0,53 \\
\hline Nov. & 260,03 & 0,23 & $2.509,33$ & 192,85 & 0,17 & $1.860,99$ & 74,44 & 29,81 & 0,42 \\
\hline Dez. & 419,64 & 0,26 & $1.563,18$ & 364,69 & 0,38 & $3.519,22$ & 140,77 & 60,53 & 1,53 \\
\hline $\begin{array}{l}\text { Total } \\
\text { anual }\end{array}$ & $3.136,53$ & \multicolumn{2}{|r|}{$30.267,54$} & $2.301,38$ & \multicolumn{2}{|r|}{ 22.208,32 } & 24 & \multirow{2}{*}{36,86} & 0,58 \\
\hline $\begin{array}{l}\text { Média } \\
\text { anual }\end{array}$ & 261,38 & 0,31 & $2.522,30$ & 191,78 & 0,22 & $1.850,69$ & 73,60 & & \\
\hline
\end{tabular}

Fonte: Dados da pesquisa

Verifica-se, na Tabela 7, que o mês de julho apresentou maior margem bruta para a atividade, ou seja, de $R \$ 505,58$ por hectare, $R \$ 0,44$ por litro de leite e o valor total de $R \$ 4.878,85$. O lucro da atividade leiteira no mês de julho foi de $R \$ 4.064,88$, o lucro por hectare foi de $R \$ 421,23$ e o lucro por litro de leite foi de $R \$ 0,37$. Além disso, o lucro por vaca, para o mês de julho, foi de $R \$ 156,34$. O percentual de lucratividade 
Contabilidade Rural e de Custos aplicada à atividade leiteira: um estudo de caso em uma propriedade rural do Oeste de Santa Catarina Cristian Bau Dal Magro, Mara Vogt, Larissa Degenhart, Leila Chaves Cunha, Fabricia Silva da Rosa

para o mês de julho foi de $55,08 \%$, e o retorno do lucro sobre o custo total foi de $R \$$ 1,23 .

Observa-se que a média mensal de margem bruta por hectare foi de $R \$ 261,38$, por litro de leite foi de $R \$ 0,31$, e a média mensal total foi de $R \$ 2.522,30$. A média mensal de lucro durante os doze meses de estudo, por hectare, foi de $R \$ 191,78$, por litro de leite foi de $R \$ 0,22$, e a média mensal de lucro total foi de $R \$ 1.850,69$. Por fim, tem-se que a média mensal de lucro por vaca foi de $\mathrm{R} \$ 73,60$ e a média de lucro anual por vaca foi de $\mathrm{R} \$ 883,24$. O Gráfico 1 demonstra a variação da receita total versus custos totais (variáveis e fixos).

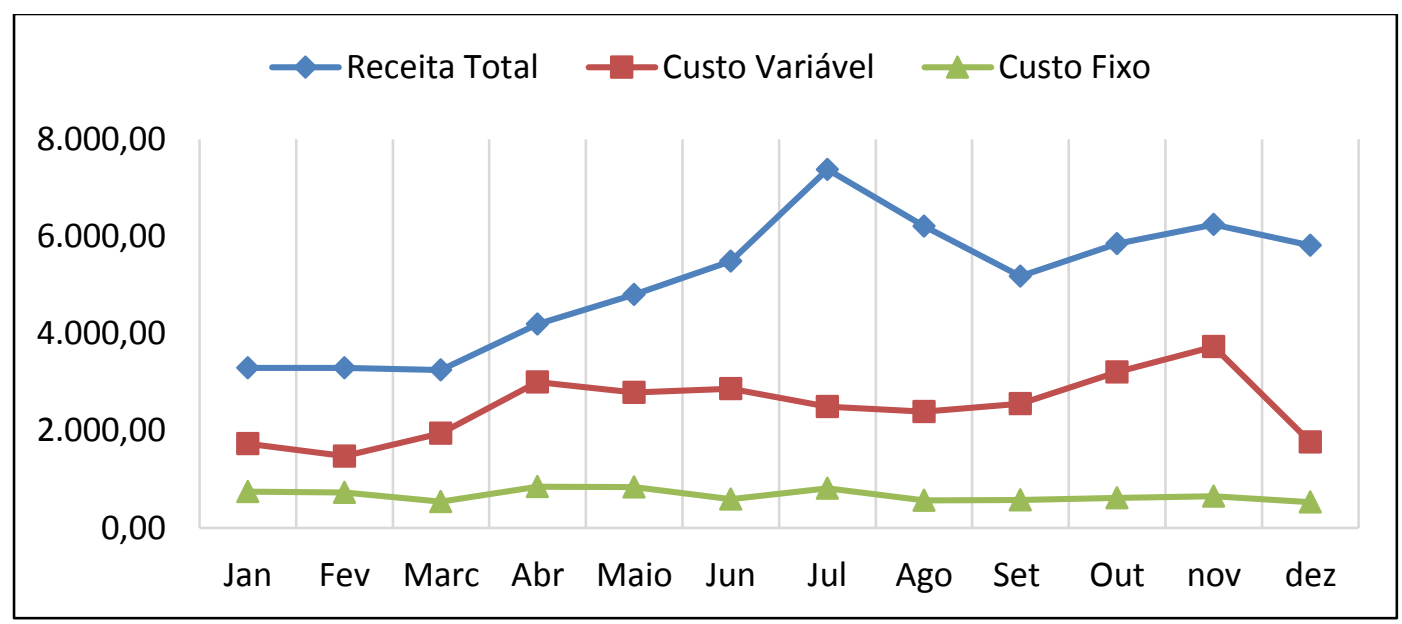

Gráfico 1 - Variação da receita total versus custos totais (variáveis e fixos) Fonte: Dados da pesquisa

Observa-se, no Gráfico 1, que a receita para os meses de janeiro, fevereiro e março ficaram praticamente inalteradas. Nos meses de abril, maio, junho e julho, a receita apresenta um aumento constante, sendo que a maior variação de aumento ocorreu entre os meses de junho e julho. Nos meses de agosto e setembro, inicia uma queda na receita de leite e, para os meses de outubro e novembro, ocorreu um pequeno aumento. Além disso, no mês de dezembro, ocorreu uma queda até a estagnação apresentada em janeiro, fevereiro e março.

Em relação aos custos variáveis, verificou-se que os meses de janeiro, fevereiro e março ficam praticamente inalterados. No mês de abril, ocorre um pequeno aumento 
Contabilidade Rural e de Custos aplicada à atividade leiteira: um estudo de caso em uma propriedade rural do Oeste de Santa Catarina Cristian Bau Dal Magro, Mara Vogt, Larissa Degenhart, Leila Chaves Cunha, Fabricia Silva da Rosa

nos custos variáveis que se mantêm entre os meses de maio, junho, julho, agosto e setembro. Nos meses de outubro e novembro, há um novo aumento e, no mês de dezembro, há uma queda brusca nos custos variáveis. Por fim, os custos fixos ficaram praticamente constantes durante os doze meses de estudo. O Gráfico 2 mostra a variação da produtividade mensal versus produtividade média anual.

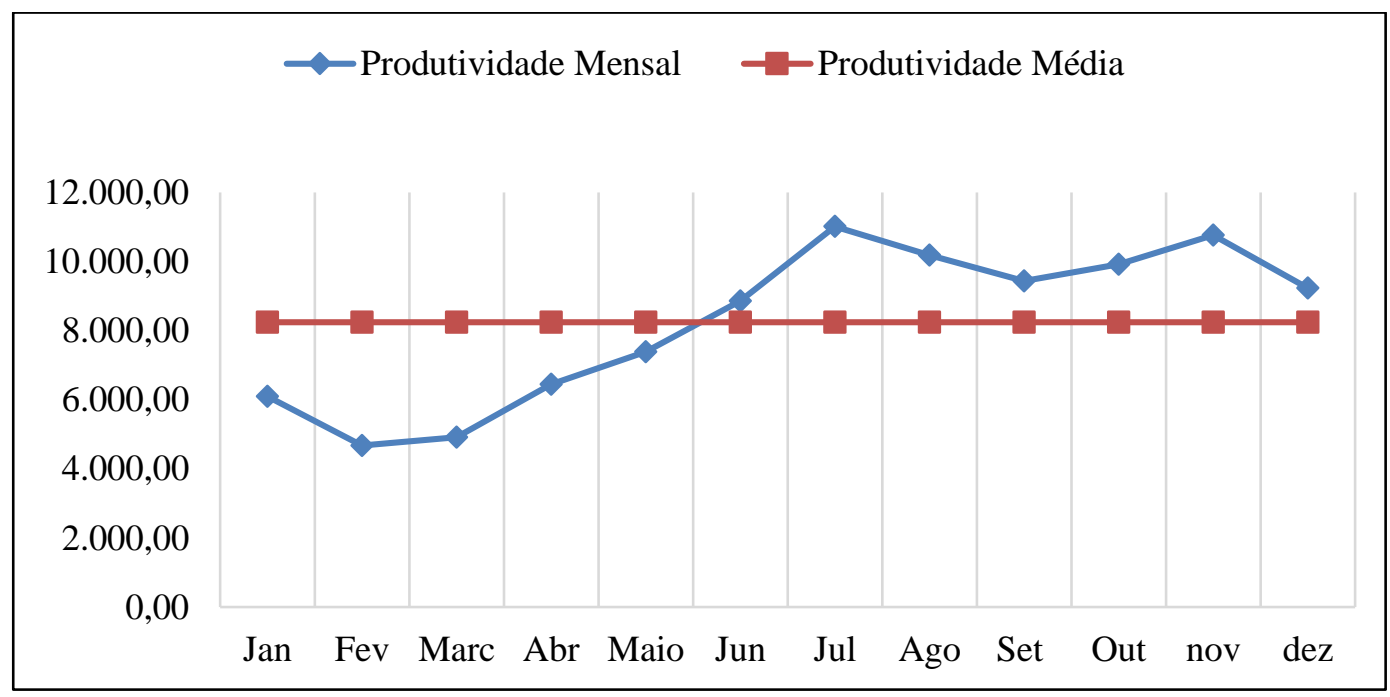

Gráfico 2 - Variação da produtividade mensal versus produtividade média do ano Fonte: Dados da pesquisa

Observa-se, no Gráfico 2, que, em relação à produtividade média mensal, os meses de janeiro, fevereiro, março, abril e maio apresentaram uma produtividade mensal abaixo da média compreendida pelos doze meses analisados. No mês de junho, a produtividade mensal foi pouco acima da média anual. O mês de julho foi o que apresentou maior produtividade e manteve-se acima da média anual para os meses de agosto, setembro, outubro, novembro e dezembro.

Com base nos achados, observa-se a importância de utilização dos conceitos e práticas da contabilidade rural e de custos aplicada à atividade rural. Diante disso, conclui-se que o produtor rural pode utilizar-se das técnicas demonstradas para melhorar seu embasamento sobre a lucratividade e competividade de suas atividades.

Contribui-se demonstrado que o detalhamento das informações, pelas técnicas de contabilidade rural e de custos, pode determinar a melhoria na tomada de decisão 
Contabilidade Rural e de Custos aplicada à atividade leiteira: um estudo de caso em uma propriedade rural do Oeste de Santa Catarina

Cristian Bau Dal Magro, Mara Vogt, Larissa Degenhart, Leila Chaves Cunha, Fabricia Silva da Rosa

dos produtores rurais e na escolha de atividades que ofereçam maior rentabilidade para a pequena propriedade rural. Portanto, os dados gerados são relevantes para demonstrar aos produtores rurais que de fato podem ser úteis para a gestão eficiente da atividade.

\section{CONSIDERAÇÕES FINAIS}

O estudo teve como objetivo verificar a contribuição da contabilidade rural e de custos para a melhoria na gestão da atividade leiteira em uma propriedade rural localizada no Oeste de Santa Catarina. Realizou-se uma pesquisa exploratória, documental e quantitativa. O período de análise compreendeu o ano de 2013. Para o alcance do objetivo proposto, foi preciso aplicar as técnicas de contabilidade rural conjuntamente com as de custos para determinar os aspectos relacionados a lucratividade, margem bruta e lucro da atividade.

Deste modo, os resultados demonstram que, no período analisado, o mês de julho apresentou maior margem bruta por hectare, por litro de leite e total. O lucro para a atividade leiteira também foi maior para o mês de julho, sendo lucro por hectare, por litro de leite e total. Além disso, verifica-se que a média de lucro do litro de leite durante o período de doze meses na propriedade rural foi de $R \$ 191,78$; por litro de leite foi de $\mathrm{R} \$ 0,22$, e a média mensal de lucro total foi de $\mathrm{R} \$ 1.850,69$.

Os resultados do estudo evidenciam que a média mensal de lucro por vaca da propriedade em estudo foi de $\mathrm{R} \$ 73,60$. Além disso, verificou-se que a lucratividade média mensal foi de $36,86 \%$. É importante salientar que, de acordo com a raça dos animais e com a forma de alimentação e tratamento, a produtividade na atividade leiteira para diferentes propriedades rurais e, até mesmo, para a propriedade em estudo, podem apresentar diferenças na produtividade em relação aos resultados deste estudo.

Este resultado não converge para os achados de Costa et al. (2013), pois, na unidade analisada pelos autores, o sistema de custeamento utilizado apresentou prejuízos em relação a cada litro de leite vendido, necessitando implementar um 
Contabilidade Rural e de Custos aplicada à atividade leiteira: um estudo de caso em uma propriedade rural do Oeste de Santa Catarina Cristian Bau Dal Magro, Mara Vogt, Larissa Degenhart, Leila Chaves Cunha, Fabricia Silva da Rosa

sistema de custeamento mais eficiente e eficaz. Nascimento et al. (2013), a partir de seu estudo, também identificaram que o sistema de Custeio Alvo necessita de ajustes, visando a melhores resultados quando da sua utilização.

O estudo desenvolvido por Kruger et al. (2013) não corrobora os achados deste estudo, pois identificaram que a maioria dos produtores analisados não separam os gastos particulares dos gastos das atividades rurais; não fazem controles na propriedade, sendo que os objetivos e as finalidades da contabilidade são desconhecidos para a maioria dos produtores analisados.

Contudo, salienta-se que o estudo de Kruger et al. (2013) foi desenvolvido em ambientes distintos e com objeto de análise distintos, mas foi possível a comparação, visto que ambos os estudos foram realizados com o intuito de observar a contribuição da contabilidade rural e de custos na gestão de propriedades rurais. Nesse sentido, a agricultura difere-se de região para região, dependendo de variados contextos agroecológicos e socioeconômicos (VAN VLIET et al., 2015).

Conclui-se que a contabilidade rural e de custos são técnicas conjuntas que, se utilizadas de maneira correta, apresentam resultados importantes para a melhoria na gestão, visando à eficiência na atividade leiteira. Diante dessa conclusão, pode-se inferir que o estudo de Ruberto et al. (2013) corrobora os achados deste estudo, pois identificaram que o processo de gestão das atividades rurais, ou seja, a utilização correta dos recursos disponíveis na propriedade, a partir da utilização de sistemas de custos, otimiza a produção, maximiza o lucro e a margem de contribuição.

O estudo desenvolvido por Novo et al. (2013) também corrobora os resultados deste estudo, visto que a produção leiteira, em seu estudo, pode ser considerada uma oportunidade interessante para a maioria dos produtores rurais analisados, pois agrega valor à produção local, criando maior renda por área rural e, até mesmo, por unidade de trabalho.

Além disso, o estudo contribuiu com a inferência de que a contabilidade rural e de custos, quando utilizada de maneira adequada e com informações úteis para a tomada de decisão da agricultora familiar, pode servir de proteção às ameaças e tendências que envolvem este ambiente, de acordo com Van Vliet et al. (2015). 
Contabilidade Rural e de Custos aplicada à atividade leiteira: um estudo de caso em uma propriedade rural do Oeste de Santa Catarina Cristian Bau Dal Magro, Mara Vogt, Larissa Degenhart, Leila Chaves Cunha, Fabricia Silva da Rosa

Esta pesquisa apresenta, como limitações, o fato de se tratar de um estudo de caso e, dessa forma, os resultados não podem ser generalizados. Além disso, o período de análise pode comprometer, de certa forma, os resultados, visto que, em algumas épocas, a produção leiteira é maior que em outras. Outrossim, as variáveis utilizadas para a análise da proposta de estudo podem ser consideradas uma limitação, pois outras variáveis poderão revelar outros resultados.

Recomenda-se, para estudos futuros, elaborar uma análise vislumbrando a comparação da lucratividade de diferentes raças de animais, determinando-se a raça que apresenta maior lucratividade, a fim de que o proprietário rural tome decisões para criação e produção, estabelecendo uma raça que apresente maior produtividade.

\section{REFERÊNCIAS}

ARGILÉS, J. M., e SLOF, E. J. (2001). New opportunities for farm accounting. European Accounting Review, 10(2):361-383.

BRASIL. Lei $n^{\circ} 11.326$, de 24 de julho de 2006. Estabelece as diretrizes para a formulação da Política Nacional da Agricultura Familiar e Empreendimentos Familiares Rurais. Disponível em: <http://www.camara.gov.br/sileg/integras/837541.pdf>. Acesso em: 27/set/2016.

BORILLI, S. P.; PHILIPPSEN, R. B.; RIBEIRO, R. G.; e HOFER, E. (2005). O Uso da Contabilidade Rural como uma Ferramenta Gerencial: Um Estudo de Caso dos Produtores Rurais no Município de Toledo - PR. Revista Ciências Empresariais da UNIPAR, 6(1): 77-95.

CALDERELLI, A. (2003). Enciclopédia contábil e comercial brasileira. (27. ed.). São Paulo: CETEC.

CALLADO, A. A. C. e CALLADO, A. L. C. (2006). Mensuração e controle de custos: um estudo empírico em empresas agroindustriais. Sistemas \& Gestão, 1(2):132-141.

CORRÊA, A. F. (2003). Modelagem de um sistema de gestão da pecuária leiteira sob os preceitos da teoria das restrições. (Dissertação de Mestrado). Universidade Federal do Rio Grande do Sul, Centro de Estudos e Pesquisas em Agronegócios, Porto Alegre, $139 \mathrm{p}$. 
COSTA, M. S. D.; LIBONATI, J. J.; e RODRIGUES, R. N. (2004). Conhecimentos sobre Particularidades da Contabilidade Rural: Um Estudo Exploratório com Contadores da Região Metropolitana de Recife. Revista ConTexto, 4(7):1-24.

COSTA, V. D. S., ASSUNÇÃO, A. B. de A; COSTA, M. M. B. da; CHACON, M. J. M. (2013). Análise de custos a partir da cadeia do valor do leite e seus derivados na região Seridó do Rio Grande do Norte. In: XX Congresso Brasileiro de Custos, 2013, Uberlândia. Anais... Uberlândia.

COMITÉ DE PRONUNCIAMENTOS CONTÁBEIS - CPC. (2009). Pronunciamento Técnico CPC 29. Ativo Biológico e Produto Agrícola. Correlação às Normas Internacionais de Contabilidade - IAS 41. Disponível em: <http://www.cpc.org.br/index.php>. Acesso em: 24/set/2016.

CREPALDI, S. A. (2004). Auditoria contábil: Teoria e prática. São Paulo: Atlas.

. (2012). Contabilidade rural: Uma Abordagem Decisorial. Atualizada de acordo com as Leis no 11.638/07, 11.941/09 e IFRS. (7. ed.). São Paulo: Atlas.

DAL MAGRO, C. B.; DI DOMENICO, D.; KLANN, R. C.; e ZANIN, A. (2013). Contabilidade rural: comparativo na rentabilidade das atividades leiteira e avícola.Custos e @gronegócioOnLine, 9(1):2-22.

FERRARI, D. L., MELlO, M. A., TESTA, V. M.; e SILVESTRO, M. L. (2005). Agricultores familiares, exclusão e desafios para inserção econômica na produção de leite em Santa Catarina. Informações Econômicas, São Paulo, 35(1): 22-36.

HOFER, E.; PACHECO, V.; SOUZA, A.; PROTIL, R. M. (2011). Relevância do Controle Contábil para o Desenvolvimento do Agronegócio em Pequenas e Médias Propriedades Rurais. Revista de Contabilidade e Controladoria, 3(1): 27-42.

INSTITUTO BRASILEIRO DE GEOGRAFIA E ESTATÍSTICA - IBGE. (2006). Censo agropecuário. Disponível em: <http://www.fao.org/fileadmin/templates/ess/ess_test_folder/World_Census_Agriculture/ Country_info_2010/Reports/Reports_4/BRA_POR_REP2_2006.pdf $>$. Acesso em: 27/set/2016.

KRUGER, S. D.; GLUSTAK, E. F., MAZZIONI, S.; ZANIN, A.; GUBIANI, C. A. (2013). A percepção dos gestores rurais sobre a utilização da contabilidade como instrumento de apoio aos estabelecimentos Rurais. In: XX Congresso Brasileiro de Custos, Uberlândia. Anais...Uberlândia. 
Contabilidade Rural e de Custos aplicada à atividade leiteira: um estudo de caso em uma propriedade rural do Oeste de Santa Catarina Cristian Bau Dal Magro, Mara Vogt, Larissa Degenhart, Leila Chaves Cunha, Fabricia Silva da Rosa

LOPES, P. F. (2006). Custos e escala de produção na pecuária leiteira: um estudo nos principais estados produtores do Brasil. (Dissertação de Mestrado). Universidade Federal de Lavras, Lavras, $86 \mathrm{p}$.

LOPES, L. B. 2007. Análise de índices de produção e reprodução em rebanhos leiteiros canadenses segundo o perfil sorológico para diarreia viral bovina e leucose enzoótica bovina. (Tese de Doutorado) em Ciência Animal. Universidade Federal de Minas Gerais (UFMG), Escola de Veterinária, 35 p.

LOPES, P. F.; REIS, R. P.; YAMAGUCHI, L. C. T. (2007). Custos e escala de produção na pecuária leiteira: estudo nos principais estados produtores do Brasil. Revista de Economia e Sociologia Rural, 45(3): 567-590.

MACDONALD, J. M.; O'DONOGHUE, E. J.; MCBRIDE, W. D.; NEHRING, R. F.; SANDRETTO, C. L.; MOSHEIM, R. (2007). Profits, costs, and the changing structure of dairy farming. Economic Research Report, 1(47):01-41.

MARION, J. C. (2012). Contabilidade rural: Contabilidade Agrícola, Contabilidade da Pecuária. (13. ed.). São Paulo: Atlas.

MARION, J. C.; SEGATTI, S. (2006). Sistema de gestão de custos nas pequenas propriedades leiteiras. Custos e @gronegócioonline, 2(2): 2-7.

MARQUES, H. (2002). Um Estudo das Informações que a Contabilidade pode prover para dar Suporte ao Processo de Gestão Operacional da Atividade Agropecuária. (Dissertação Mestrado). Universidade Federal de Santa Catarina, 149 p.

MATOS, L. L. D. (2002). Estratégias para Redução do Custo de Produção de Leite e Garantia de Sustentabilidade da Atividade Leiteira. In: Simpósio sobre Sustentabilidade da Pecuária Leiteira na Região Sul do Brasil, Maringá, Anais... Maringá.

MEDINA, G.; ALMEIDA, C.; NOVAES, E.; GODAR, J.; e POKORNY B. (2015). Development conditions for family farming: Lessons from Brazil. World Development, (74): 386-396.

MENDES, C. I. C.; TEIXEIRA, S. R. (2009). Controle da Produção Leiteira e a Demanda por Sistemas Computacionais Simples. In: Embrapa Informática Agropecuária-Artigo em anais de congresso (ALICE). In: Congresso Brasileiro de Agroinformática, (7.ed.). Viçosa, 2009. Anais... Viçosa.

NASCIMENTO, J. C. H. B. D.; BERNARDES, J. R.; SOUZA, W. D. D.; LANCINI, S. P. (2013). Custeio alvo, ferramenta estratégica de suporte às decisões de produção? Um estudo multi casos no Vale do São Francisco. Custos e @gronegócioonline, 9(3). 
Contabilidade Rural e de Custos aplicada à atividade leiteira: um estudo de caso em uma propriedade rural do Oeste de Santa Catarina Cristian Bau Dal Magro, Mara Vogt, Larissa Degenhart, Leila Chaves Cunha, Fabricia Silva da Rosa

NOVO, A. M.; SLINGERLAND, M.; JANSEN, K.; KANELLOPOULOS, Argyris e GILLER K. E. (2013). Feasibility and competitiveness of intensive smallholder dairy farming in Brazil in comparison with soya and sugarcane: Case study of the Balde Cheio Programme. Agricultural Systems, 121, 63-72.

RANKBRASIL. (2012). Recordes Brasileiros. Disponível em: <http://www.rankbrasil.com.br/Recordes/Noticias/06rz/Brasil_E_O_3_Maior_Produtor_D e_Leite_Do_Mundo> Acesso em: 22 jul. 2014.

RUBERTO, I. V. G.; MARETH, T.; PAIM, E. S. E.; PIENIZ, L. P. (2013). Contribuição da programação linear na gestão de custos e na produtividade em uma propriedade rural. Custose @gronegócio on line, 9(1):185-202.

TOADER, M.; ROMAN, G. V. (2015). Family Farming-Examples for Rural Communities Development. Agriculture and Agricultural Science Procedia, 6(1):89-94.

VAN VLIET, J. A.; SCHUT, A. G. T.; REIDSMA, P.; DESCHEEMAEKER, K.; SLINGERLAND, M.,;VAN DE VEN, G. W. J.; GILLER, K. E. (2015). De-mystifying family farming: features, diversity and trends across the globe. Global Food Security, 5(1): 1118.

VILCKAS, M. (2004). Determinantes da tomada de decisão sobre as atividades produtivas rurais: Proposta de um Modelo para a Produção Familiar. São Carlos, RS. (Dissertação de Mestrado). Universidade Federal de São Carlos, 144 p.

Data de Submissão: 14/06/2016

Data de Aceite: 10/10/2016 